\title{
Use of ratings of perceived exertion for predicting maximal work rate and prescribing exercise intensity in patients taking atenolol
}

School of Sport, Health and Physical Education Sciences, University of Wales, Bangor, Gwynedd, LL57 2EN, United Kingdom R G Eston

Grosvenor Nuffield Hospital, Wrexham Rd, Chester, CH4 7QP, United Kingdom M Thompson

Correspondence to: Dr Eston.

Accepted for publication 18 December 1996

Roger G Eston, Marilyn Thompson

\begin{abstract}
Objective-The purpose of this study was to assess the efficacy of Borg's rating of perceived exertion (RPE) scale to predict maximal exercise levels to control exercise intensity in patients taking atenolol for the treatment of essential hypertension. Normally, a standard formula (220 - age) is used for calculating a percentage of exercise intensity, but $\beta$ blockade can cause reductions in maximal heart rate of between 20 and $30 \%$.
\end{abstract}

Methods-Patients were split into a control group-10 men and 10 women, aged 50 (SD 12) and 46 (9) respectively, who had risk factors for cardiovascular disease but were not taking any drugs, and a treatment group-11 men and 11 women, aged 53 (13) and 55 (13) respectively, who were established on $25-100 \mathrm{mg}$ of atenolol. All patients performed two submaximal tests on a cycle ergometer. Test 1 was an estimation test, during which the RPE was reported for each increment in work rate. Test 2 was an RPE production test, during which the patient regulated the work rate according to his/her perception of effort at four predetermined points on the RPE scale (RPE 9, 13, 15, 17).

Results-In both tests the individual correlations ( $r$ ) between RPE, heart rate, and work rate ranged from 0.96 to 0.99 . Analysis of variance showed no significant difference in maximal heart rate and maximal power output for the control group when predicted from the regression lines of RPE versus heart rate and RPE versus power output in the estimation test. However, the prediction of maximal power output was lower in the women in the control group and patients in the treatment group when this was predicted from the effort production protocol $(P<0.01)$. When exercise intensity at each RPE was expressed relative to maximal power output there were no differences between treatment and control groups. Conclusion-The findings from this study confirmed the strong positive relation between RPE, heart rate, and work rate in these patients in both passive effort estimation and active effort production protocols. However, caution in applying these procedures is required because the prediction of maximal exercise levels may be lower when effort production procedures are used.

(Br F Sports Med 1997;31:114-119)

Keywords: exertion; $\beta$ blockers; exercise intensity; atenolol

$\beta$ Blocking drugs have become one of the most commonly prescribed drug treatments for cardiovascular disease since their introduction in the early 1960s. The immediate and most obvious effect of $\beta$ blocker treatment is a reduction in heart rate due to competitive blocking of $\beta$ adrenoreceptors. Hence, during submaximal exercise, patients receiving $\beta$ blocker treatment experience moderate to large reductions in heart rate of between 20 and $30 \% .^{1-5} \mathrm{~A}$ combination of $\beta$ blocker treatment and dynamic physical exercise is considered beneficial for many patients with cardiovascular disease. Ideally, appropriate exercise intensity prescription for patients receiving $\beta$ blockade treatment requires a known maximal heart rate, but this is difficult to determine from submaximal exercise tests owing to the moderate to large reductions in heart rate. Although $\beta$ blocker treatment decreases maximal heart rate, it does not alter the relation between the percentage of maximal heart rate and the percentage of maximal oxygen uptake. $^{56}$

The Borg 15 point rating of perceived exertion (RPE) scale $^{7}$ is often applied during graded exercise testing to obtain a subjective estimation of exercise intensity, and as an accurate predictor of functional capacity in healthy adults. ${ }^{8-11}$ The rationale supporting its use is its strong relation with heart rate, oxygen uptake, minute ventilation, and other physiological variables within a wide range of healthy and clinical populations. ${ }^{6}{ }^{12-14}$

Many studies have explored the relation between effort perception and exercise intensity in patients with cardiovascular disease ${ }^{15-24}$ and healthy subjects whose cardiovascular response has been mediated by $\beta$ blockers. ${ }^{25-27}$ Studies have confirmed that the RPE scale can be used to elicit undifferentiated estimates of effort perception in patients with hypertension, intermittent claudication, and post-myocardial infarction, although few studies have explored the use of RPE as the controlling variable of exercise intensity in these patients and few have used it to predict maximal functional capacity in these patients. $^{6}$ There are no studies available whereby RPE has been used to 
Table 1 Descriptive statistics for age, height, mass, body mass index (BMI), and resting values for systolic blood pressure (SBP), diastolic blood pressure (DBP) $(\mathrm{mm} \mathrm{Hg})$, and resting heart rate (HR) of the control group and the $\beta$ blocker group. Values are mean $(S D)$

\begin{tabular}{|c|c|c|c|c|c|c|c|}
\hline & \multicolumn{4}{|c|}{ Anthropometric } & \multicolumn{3}{|c|}{ Cardiovascular } \\
\hline & $\begin{array}{l}\text { Age } \\
\text { (years) }\end{array}$ & Height (m). & $\begin{array}{l}\text { Mass } \\
(\mathrm{kg})\end{array}$ & $B M I$ & $S B P$ & $D B P$ & $H R$ \\
\hline \multicolumn{8}{|c|}{ Control group } \\
\hline \multicolumn{8}{|c|}{ Men } \\
\hline Mean & 49.5 & 1.75 & 82.7 & 27.7 & 141.0 & 88.0 & 77.0 \\
\hline SD & 12.1 & 0.07 & 7.9 & 2.3 & 20.0 & 7.4 & 6.7 \\
\hline \multicolumn{8}{|l|}{ Women } \\
\hline Mean & 45.5 & 1.67 & 82.0 & 28.8 & 129.8 & 83.1 & 77.9 \\
\hline SD & 9.4 & 0.06 & 19.4 & 6.4 & 13.7 & 7.1 & 11.5 \\
\hline \multicolumn{8}{|c|}{ Treatment group } \\
\hline \multicolumn{8}{|l|}{ Men } \\
\hline Mean & 53.1 & 1.74 & 79.5 & 26.5 & 141 & 86.5 & 55.9 \\
\hline SD & 12.7 & 0.07 & 8.6 & 2.3 & 8.6 & 7.6 & 7.5 \\
\hline \multicolumn{8}{|l|}{ Women } \\
\hline Mean & 55.1 & 1.64 & 65.9 & 24.8 & 147.7 & 86.4 & 57.7 \\
\hline SD & 12.7 & 0.07 & 15.5 & 4.7 & 13.3 & 7.4 & 7.3 \\
\hline
\end{tabular}

predict maximal work rate in patients taking atenolol (a cardioselective $\beta$ blocker).

METHODOLOGICAL STRATEGIES AND RPE

Commonly, RPE is used as a dependent variable whereby the individual gives a subjective estimation of intensity of effort (estimation protocol). The subjective estimates are then usually compared against some measure of exercise intensity on a subsequent occasion. For example, Shephard et al, using cycle ergometry as the exercise mode, recently applied this method to examine before and after training responses in patients who had received cardiac transplantation. ${ }^{24}$

Another strategy, which has not been used as often, is to manipulate the RPE as the independent variable to regulate exercise intensity. In this way, the individual produces an effort perceived to be of a magnitude related to the RPE scale (production protocol). ${ }^{28}$ One variation of the production protocol, first applied by Eston et $a{ }^{29}{ }^{29}$ required subjects to exercise at a steady state intensity corresponding to predetermined RPEs of 9, 13, and 17. Practice appears to improve the reliability of this method from trial to trial even at lower RPEs. ${ }^{30}$ There has been increased interest in the use of production protocols in healthy adults and children, but exploration of this technique with patients who have cardiovascular disorders is limited.

It is known that the relation between RPE and heart rate is altered with $\beta$ blocking agents. ${ }^{25}$ This makes heart rate an unreliable predictor of perceived exercise intensity for the purpose of prescriptive training. Additionally, the relation between oxygen uptake $\left(\mathrm{Vo}_{2}\right)$ and heart rate (HR) changes after $\beta$ blockade, though the relation between $\% \mathrm{VO}_{2} \max$ and $\% \mathrm{HR}$ max is minimally altered. ${ }^{5}$

If the more stable relation between $\% \mathrm{Vo}_{2}$ max and RPE, independent of $\beta$ blockade, exists, then the absolute RPE may be used as a predictor of relative exercise intensity in this patient group.

The purpose of this investigation was to assess the efficacy of RPE to predict the maximal work rate and to prescribe exercise intensity in patients taking atenolol for essen- tial hypertension. A unique aspect of this study was the use of the RPE as the independent variable to elicit exercise intensities according to predetermined RPE levels.

\section{Methods}

SUBJECTS

All subjects taking part in the study were patients at the Garden Lane Medical Centre (GLMC), Chester, United Kingdom, who had agreed to participate in a "Healthy Heart" programme, developed as a result of recommendations from the Department of Health. ${ }^{31}$ The Shaper risk assessment model ${ }^{32}$ was used as a tool to identify a control group of patients (10 men and 10 women) at risk of developing coronary heart disease. Criteria were that these patients scored 1000 or more on the Shaper risk assessment profile but were not receiving atenolol. The treatment group (11 men and 11 women) were taking atenolol (25-100 mg) once daily for essential hypertension. Criteria for selection of patients in this group were: under 70 years of age and where exercise prescription was medically recommended for patients stabilised on atenolol for a minimum of three months. The following exclusions applied: patients taking a combination of atenolol and another heart specific drug; patients receiving thiazide diuretics, patients with postmyocardial infarction or past cardiac operation, and patients whose physical condition would not allow completion of testing-for example, a musculoskeletal degenerative condition. Table 1 shows descriptive statistics of the subjects. None of the subjects was a regular exerciser before joining the "Healthy Heart" programme.

\section{PROCEDURES}

\section{Pretest measurements}

Body mass index (BMI) was calculated using the Quetelet index (mass $(\mathrm{kg}) /$ height $\left(\mathrm{m}^{2}\right)$ ). Resting heart rate was recorded after patients had been sitting quietly for five minutes, with a Sport Tester PE 3000 heart rate monitor (Polar, Finland). After resting heart rate was recorded, blood pressure was measured by an Omron soft cuff autoinflation/deflation monitor with pressure/pulse averaging function. All measurements were taken on the left arm. All patients were informed of the risks and benefits associated with testing and gave written consent to take part in accordance with the Garden Lane Medical Centre policy.

\section{Exercise test procedure}

Familiarisation with the experimental protocol began with an explanation of the test procedure followed by a short practice at pedalling at 60 $\mathrm{rpm}$ at varied work rates, and practice at using the RPE scale within the range RPE 9 and RPE 17.

Tests were conducted in two stages, with a minimum of two days between each test. The tests were timed to occur at midday to maintain a standard and convenient time for patient attendance. This had particular relevance to patients in the treatment group, as this was an 


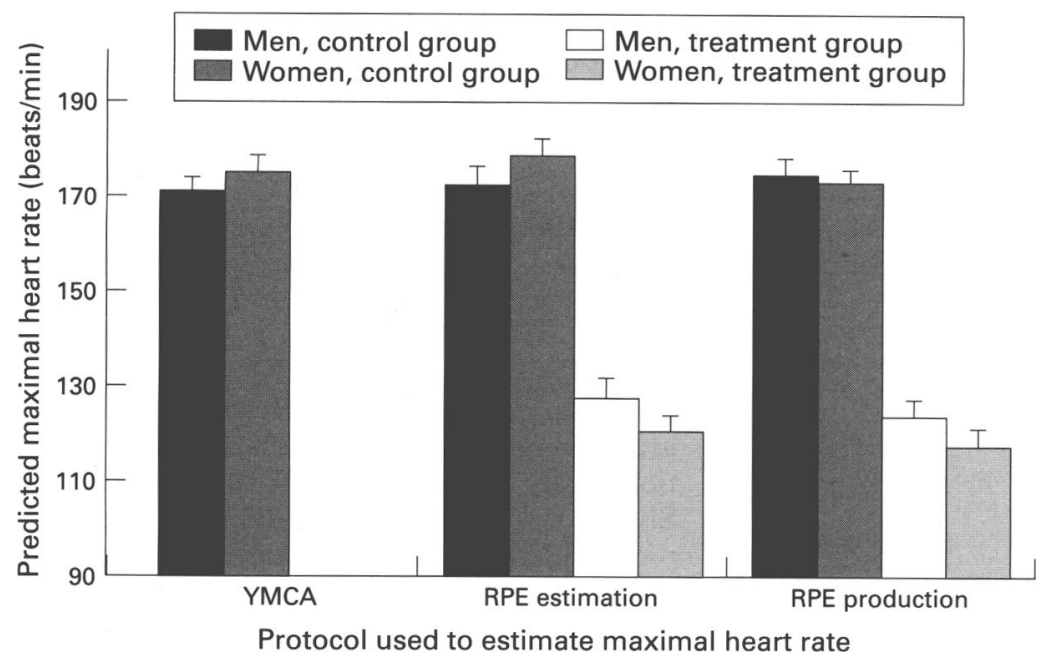

Figure 1 Comparison of maximal heart rates predicted from the YMCA submaximal graded exercise test (heart rate $=220$ - age), and from the rating of perceived exertion $(R P E)$ estimation and production protocols when $R P E=20$. Values are means (SEM).

optimum time for the stability of $\beta$ blocking drug effects.

Submaximal graded exercise test

Effort estimation data were based on the RPE obtained during the graded exercise test. The same cycle ergometer (Monark Ergomedic $818 \mathrm{E}$ ) was used for all testing. A large cardboard RPE scale was visible at all times. RPE was reported in the last 15 seconds of the final minute for each increment of work rate. The control group performed the YMCA cycle ergometry protocol (as described by the American College of Sports Medicine ${ }^{33}$ ). This is a submaximal graded exercise test with an initial bout of $25 \mathrm{~W}$. Subsequent three to four minute work rates are designed to raise the heart rate to $110-150$ beats/min to predict the maximal oxygen uptake or maximal work rate. The RPE and work rate data from this test were also used to confirm the reliability of the RPE $v$ work rate relation and to predict the maximal work rate.

\section{Protocol for the submaximal graded exercise test for the patients receiving atenolol}

The protocol for men in the treatment group was four work rates starting at $25 \mathrm{~W}$, with increments of $25 \mathrm{~W}$ every three minutes, up to $100 \mathrm{~W}$. For women in the treatment group the work rate started at $20 \mathrm{~W}$ and increased by 15 $\mathrm{W}$ every three minutes, up to $65 \mathrm{~W}$. The reason for the different exercise test for the treatment group was because the low heart rates on the initial work rate of $25 \mathrm{~W}$ would have meant progression to the highest work rate at the next incremental stage in the YMCA protocol. In addition, our previous experience with unfit women not used to exercising was that they found it difficult to maintain a pace of $60 \mathrm{rpm}$ at $100 \mathrm{~W}$, which is one of the prescribed work rates in the YMCA test protocol. This has also been noted by Siconolfi et al. ${ }^{34}$

\section{Effort production test}

The effort production test was performed two days later. In this test the patient was requested to work at RPEs of $9,13,15$, and 17 , by manipulating the resistance control themselves to elicit the predetermined, steady state RPE. A few minutes were allowed for patients to become accustomed to this method and then a three minute bout at the predetermined RPE was undertaken. Heart rate and work rate were measured in the last 15 seconds. The subject was then instructed to select a work intensity that corresponded to the next highest RPE.

\section{Prediction of maximal heart rate and maximal} work rate

Maximal heart rate and maximal work rate were predicted by three separate methods. For the control group only, the maximal heart rate was predicted from the 220 - age formula, as recommended by the YMCA protocol. Heart rate and work rate were also plotted against RPE from both the estimation and the production protocol for each subject from both groups. Individual correlations from linear regression analysis for both protocols ranged from 0.96 to 0.99 in all cases. This allowed prediction of maximal heart rate and work rate when using the RPE from the estimation test and when the RPE was applied as the independent, controlling variable in the effort production test. Maximal values were predicted by inserting RPE 20 into each individual regression equation derived from the heart rate $v \mathrm{RPE}$ and work rate $v \mathrm{RPE}$ relations.

\section{STATISTICAL ANALYSIS}

To determine differences in the prediction of maximal heart rate and work rate in the control group a $2 \times 3$ analysis of variance (gender $\times$ protocol), with repeated measures on protocol, was conducted. A separate analysis of variance (ANOVA) was conducted to determine differences in maximal work rate and heart rate between the control group and the treatment group using both exercise test protocols. Thus a $2 \times 2 \times 2$ ANOVA, (protocol $\times$ group $\times$ gender) was used to determine differences. The YMCA data were not included in this analysis owing to the obvious problems of predicting maximal heart rate by this procedure in patients taking $\beta$ blockers. A further separate three factor ANOVA (group $\times$ gender $\times \mathrm{RPE}$ ) was applied to determine differences in the relative exercise intensity elicited at RPEs of 9 , 13,15 , and 17 from the effort production test.

\section{Results}

COMPARISON OF CONTROL GROUP VALUES

Predicted maximal heart rate

There were no main effects for gender $\left(F_{1,18}=\right.$ $0.43)$ or protocol $\left(F_{2,36}=0.30\right)$ on predicted maximal heart rate. However, there was a significant interaction of gender by protocol $\left(F_{2,36}=4.25, P<0.05\right)$. Scheffé post hoc tests showed that the prediction of maximal heart rate from the effort production test was lower in the women's group (fig 1).

Predicted maximal work rate

There was a significant main effect for gender on maximal work rate, which indicated that men had a higher predicted maximal work rate in all three protocols $\left(\mathrm{F}_{1,18}=10.57, \mathrm{P}<0.01\right)$. 


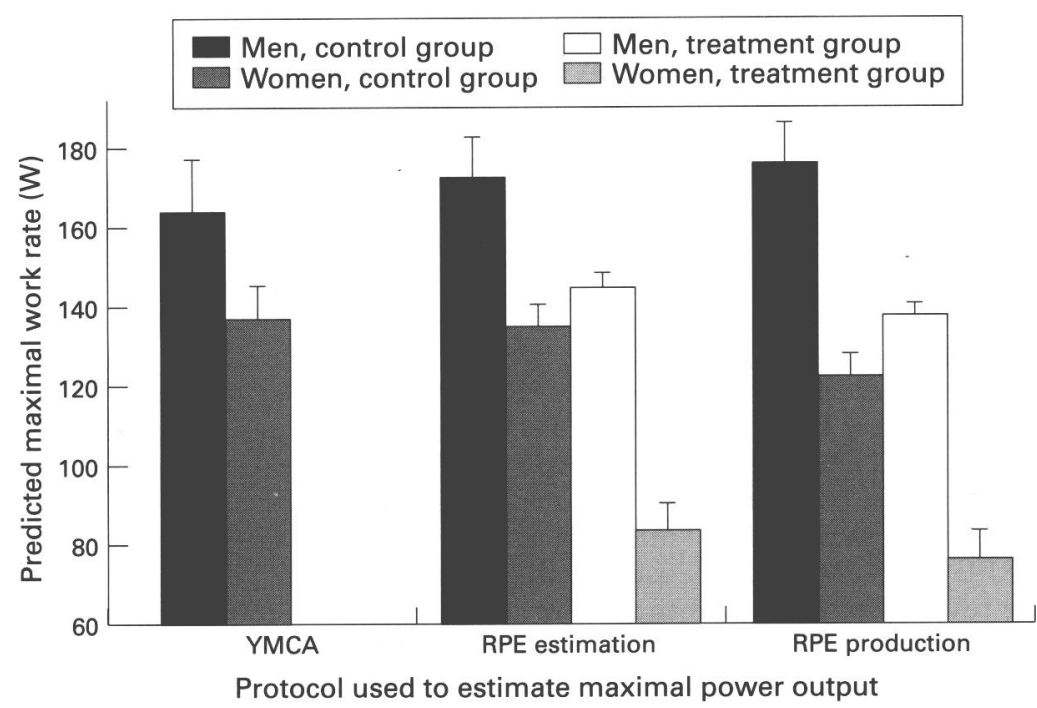

Figure 2 Comparison of maximal power output predicted from the YMCA submaximal graded exercise test and from the rating of perceived exertion (RPE) estimation and production protocols when $R P E=20$. Values are means (SEM).

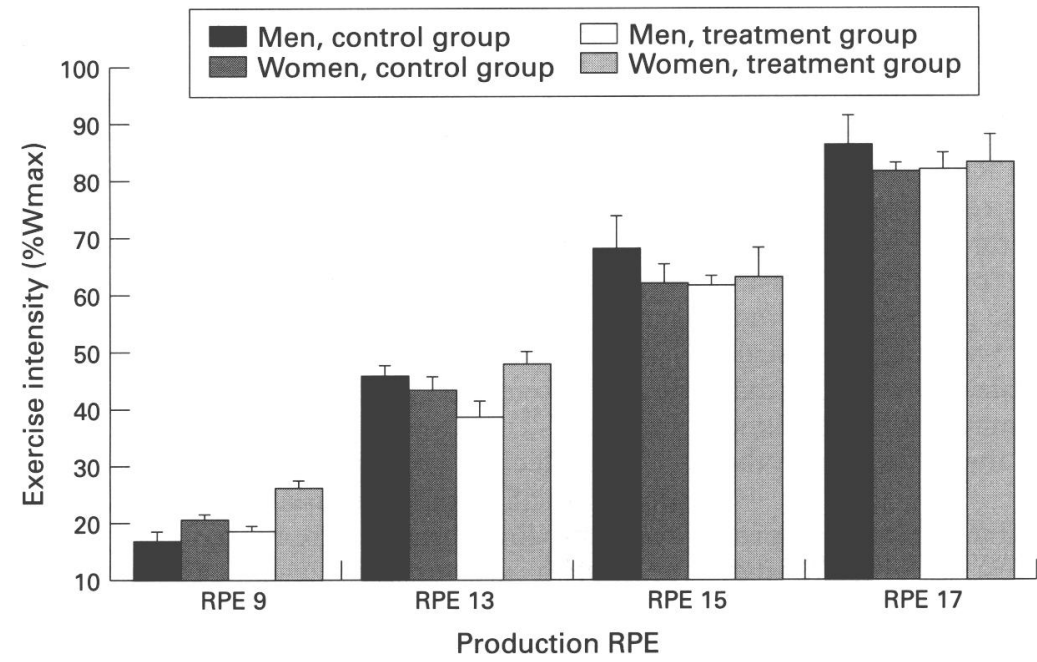

Figure 3 Comparison of the relative exercise intensity (expressed as a proportion of the predicted maximal work rate (\%Wmax)) produced at $R P E$ units of $9,13,15$, and 17, during the effort production protocol. Values are means (SEM).

There was no main effect for protocol $\left(\mathrm{F}_{2,36}=\right.$ 0.69). There was, however, a significant interaction of gender by protocol $\left(\mathrm{F}_{2,36}=4.34\right.$, $\mathrm{P}<0.05)$. Scheffé post hoc tests showed that the prediction of maximal work rate from the effort production test was lower in the women's group (fig 2).

\section{COMPARISON OF CONTROL AND TREATMENT} GROUPS

Predicted maximal work rate

A comparison of the control and treatment group showed that, as expected, gender produced a significant effect, with men having a higher predicted maximal work rate than women $\left(F_{1,38}=63.7, P<0.01\right)$. A significant main effect for group $\left(F_{1,38}=36.8, P<0.01\right)$ showed that the $\beta$ blocker treatment group had a lower predicted maximal work rate than the control group. There was also a significant effect for protocol $\left(\mathrm{F}_{1,38}=11.3, \mathrm{P}<0.01\right)$. The maximal work rate predicted from the RPE production protocol was lower than that predicted by the RPE estimation protocol (fig 2).
Predicted maximal heart rate

As expected the treatment group had a lower predicted maximal heart rate than the control group $\left(\mathrm{F}_{1,38}=219.2, \mathrm{P}<0.01\right)$. There was no main effect for gender $\left(F_{1,38}=0.40\right)$ or protocol $\left(F_{1,38}=0.56\right)$ on maximal heart rate (fig 1$)$.

Comparison of the relative exercise intensity at each submaximal $R P E(9,13,15,17)$ in the effort production protocol

The work rate at each RPE was expressed as a proportion of the predicted maximal work rate (\%Wmax). As expected there was a main effect for RPE on exercise intensity $\left(F_{3,114}=910.1\right.$, $P<0.01)$. Scheffé post hoc tests showed that exercise intensity increased with each subsequent RPE production level. There was no significant interaction of group by $\operatorname{RPE}\left(\mathrm{F}_{3,114}=\right.$ 2.57). Thus, although the absolute work rates were higher in the control group of men and women when these were expressed relative to the maximum work rate, there was no difference between the groups. There was, however, a significant interaction of gender by RPE $\left(F_{3,114}=4.08, P<0.01\right)$. Scheffé post hoc tests showed that the exercise intensities elicited at RPE production levels of 9 and 13 were higher for women in the treatment group than for women in the control group and men in the treatment group (fig 3).

\section{Discussion}

The results from this study provide some evidence that RPE may be used to predict maximal functional capacity in patients receiving atenolol for the treatment of essential hypertension. In the control group of men and women the prediction of maximal work rate at the age predicted maximal heart rate from the YMCA submaximal test was similar to that predicted by the RPE, when the RPE was used as the dependent variable (effort estimation). However, when the RPE was used as the controlling factor in the effort production protocol-that is, as the independent variable, the prediction of maximal heart rate and maximal work rate were lower in the women's control group.

It would appear from the limited data available in this study that some degree of caution is required when predicting maximal functional capacity from an effort production protocol, particularly in women who have risk factors for congenital heart disease.

It seems that when the women were requested to select an exercise intensity to correspond with a given RPE, they became more conservative and tended to overestimate the exercise intensity that they selected. Thus the RPE was high relative to the exercise intensity. The effect of this would be to decrease the prediction of maximal functional capacity at RPE 20. Perhaps this might be due to a lack of exercise experience in this group. This group of women were sedentary-that is, not used to exercising regularly in activities of daily living, and were not participating in extra exercise.

Separate analyses were performed to compare differences between the predicted maximal values from the RPE estimation test and 
RPE production tests in the treatment and control groups. As expected, the predicted maximal heart rate and the predicted maximal work rate were lower in the treatment group when the RPE was used to predict these values (figs 1 and 2). An interesting observation was the significantly lower maximal work rate predicted by the production protocol in the treatment group and in the women's control group. Although the magnitude of this difference was small (5-10\%), it again indicates that attempts to measure exercise intensity with the RPE should consider the way in which the RPE is used in the baseline test. When the $\beta$ blocker group and the women in this study were asked to exercise at a specific RPE they underestimated the level of exercise resistance required or, conversely, they overestimated the RPE for a given work rate. In any case, like the women in the control group, the patients in the treatment group became more conservative when the RPE was used as the independent variable to control the exercise level. This caused a significant decrease in the prediction of maximal work rate when it was extrapolated from the RPE versus work rate regression line.

A degree of caution is therefore recommended when transferring RPE from "estimation" tasks (that is, RPE recorded during a graded exercise test) to using RPE to self regulate exercise intensity in "production" tasks. The distinction between the process of estimation and production tasks with the RPE scale was first alluded to by Noble, ${ }^{35}$ who noted that equivalent exercise levels may not be repeated at the same RPE owing to the difference in the process.

Eston and Williams used a similar RPE production and estimation test to ours, though oxygen uptake was measured by open circuit spirometry. ${ }^{30}$ Subjects performed steady state exercise at RPE production levels of 9,13 , and 17 on three separate occasions after performing an estimation test. The accuracy of effort production improved on the second and third trial for all RPEs, particularly as the exercise intensity increased. Unfortunately, in our study it was not possible to repeat the effort production trials, which is an important consideration in learning how to use the RPE.

Ekblom and Goldbarg observed that submaximal oxygen uptake and heart rate were lower for a given RPE for cycle ergometry than for treadmill work. ${ }^{25}$ Thus exercise prescription based on RPE should consider the exercise mode because the source of effort perception varies and influences the magnitude of the rating. This was recently alluded to by Shephard et al in their study on patients who had had a cardiac transplant. ${ }^{24}$ Because of local loading of the quadriceps, both muscle specific and overall ratings of perceived exertion tend to be higher in relation to percentage of peak $\mathrm{Vo}_{2}$ during cycling than during walking, jogging, or treadmill exercise. ${ }^{36}$ In this study an RPE rating of 13 produced a relative exercise intensity range of $39-48 \%$ of maximal, which is somewhat lower than that reported in previous studies using cycling and effort production procedures with normal, healthy subjects. ${ }^{30}$ Shephard et $a l^{4}$ recently noted a mean value of $50 \% \mathrm{Vo}_{2}$ max at RPE 13 in a group of sedentary men of similar age to those in this study, though it should be noted that their protocol was based on passive effort estimation procedures. As previously indicated, we suspect that subjects in this study adopted a conservative approach when using the effort production procedure.

Evidence suggests that the RPE is mediated by the pedalling rate on a cycle ergometer as higher RPEs are reported at slower pedalling rates. ${ }^{38}$ In our study the pedalling rate was maintained at a comfortable pace $(60 \mathrm{rpm})$ and so did not cause the relatively low exercise intensity at each RPE. Cycle ergometry was used in this study, and it is pertinent to note that there is a greater test-retest reliability of $\mathrm{RPE}$ during cycle ergometry than during treadmill running. This is attributed to the greater localisation of muscle fatigue during cycle ergometry, allowing more accurate assessment of the intensity of the perceptual signals. In addition, the attentional focus is not interrupted by attention to balance and stability, as it is with treadmill exercise. ${ }^{36}$

Similar relative exercise intensities were produced at each RPE, though the women in the $\beta$ blocker group tended to underestimate the intensity of exercise at the lowest RPE. This may be attributable to limited exercise experience or a problem in adjusting to the procedure in the initial phase. It has already been noted that RPE is less accurate at the lowest intensities, particularly when practice is limited. ${ }^{30} 39$

The effect of $\beta$ blockade on RPE depends on the type of $\beta$ blocker used. Non-selective $\beta$ blockers (for example, propranolol) are associated with greater muscle fatigue, increased peripheral resistance, and greater reductions in maximal oxygen uptake. ${ }^{40-42}$ Owing to the cardioselective action of atenolol, it is likely that there was less local muscle fatigue, which is an important consideration when using RPE as a means of regulating exercise intensity in these patients.

In conclusion, our findings provide some support for the use of the RPE to predict maximal work rate in patients receiving $\beta$ blocker treatment, particularly when it is used in an estimation mode. It seems that predictions of exercise intensity and maximal functional capacity using the RPE must consider the process by which it is used, owing to the essential differences in the process of estimation and production. One is a passive (effort estimation) response, whereas the other is an active (effort production) response using the RPE. The reasons for the differences remain uncertain, and are worthy of further investigation. Nevertheless, the findings from this preliminary investigation lend support for the use of RPE in some cardiac rehabilitation settings and indicate potential areas of exploration.

1 Reybrouck T, Amery A, Billnet I. Haemodynamic response to graded exercise after chronic beta-adrenergic blockade. $\mathcal{F}$ Appl Physiol 1977;42:133-8.

2 Lund-Johansen P. Central haemodynamic effects of betablockers in hypertension: a comparison between atenolol metoprolol, timolol, penbutolol, aprenolol, pindolol and bunirolol. EurHeart f 1983;4(suppl D):1-12. 
3 MacFarlane BJ, Hughson RL, Green HJ, Walters DJ, Ramsey DA. Effects of oral propranolol and exercise protoco on indices of aerobic function in normal man. Can $\mathfrak{f}$ Physiol Pharmacol 1983;61:1010-16.

4 Wilmore JH, Gordon AE, Freund BJ, Hartzell AA, Jlika SM Joyner MJ, et al. Cardiorespiratory alterations consequen to endurance exercise training during chronic betaadrenergic blockade. Am $\mathcal{f}$ Cardiol 1985;55:142D-8D.

5 Van Baak MA. Beta-adrenergic blockade and exercise: an update. Sports Med 1988;2:389-412.

6 Eston RG, Connolly DA. The use of ratings of perceived exertion for exercise prescription in patients receiving betablocker therapy. Sports Med 1996;21:176-90.

7 Borg G. Perceived exertion as an indicator of somatic stress. fournal of Rehabilitation Medicine 1970;2:92-8.

8 Morgan WP, Borg G. Perception of effort in the prescription Morgan WP, Borg G. Perception of effort in the prescription of physical activity. In: Craig T, ed. Mental health and emotional aspects of sports.

9 Wilmore JH, Roby FB, Stanforth PR, Buono MJ, Constable $\mathrm{SH}, \mathrm{Tsao} \mathrm{Y}$, et al. Ratings of perceived exertion, heart rate and work rate in predicting maximal oxygen uptake during submaximal cycle ergometry. The Physician and Sports Medicine 1986;14:133-43

10 Ljunggren G, Johannson S. Use of submaximal measures of perceived exertion during bicycle ergometer exercise as predictors of maximal work capacity. $\mathcal{F}$ Sports Sci 1988;6: 189-203.

11 Johnson JH, Prins A. Prediction of maximal heart rate during a submaximal work test. $\mathcal{F}$ Sports Med Phys Fitness 1991;31:44-7.

12 Pandolf KB. Advances in the study and application of perceived exertion. Exerc Sport Sci Rev 1983;11:118-58.

13 Werceived exertion. Exerc Sport $S c i$ Rev $1983 ; 11: 118-58$. dimension in vigorous exercise programmes, with particudimension in vigorous exercise programmes, with particular reference to the use of the
Sports Med 1989;8:177-89.

14 Watt B, Grove R. Perceived exertion: antecedents and applications. Sports Med 1993;15:225-42.

15 Williams MA, Fardy PS. Limitations in prescribing exercise from perceived exertion, onset of symptoms of fixed hear rates in cardiac patients (abstract). Med Sci Sports Exerc 1979;11:111.

16 Van Herwaarden CLA, Binkhorst RA, Fennis JFM, Van T'Laar, A. Effects of propranolol and metoprolol on haemodynamic and respiratory indices and on perceived exertion during exercise in hypertensive patients. Br Hear f 1979;41:99-105.

17 Gutmann MC, Squires RW, Pollock ML, Foster C, Anholm J. Perceived exertion-heart rate relationship during exercise testing and training in cardiac patients. Fournal of Cardioptesting and training in cardiac patie

18 Pollock ML, Foster C, Rod JL, Wible G. Comparison of Pollock ML, Foster C, Rod JL, Wible G. Comparison of methods for determining exercise training intensity for cardiac patients and healthy adults. In: Kellerman JJ, ed. Comprehens.

19 Pollock ML, Jackson AS, Foster C. The use of the perception scale for exercise prescription. In: Borg G, Ottoson $\mathrm{D}$, eds. The perception of exertion in physical work. New York: Macmillan, 1986:161-76. (Wenner-Gren international symposium series.

20 Squires RW, Rod JL, Pollock ML, Foster C. Effect of propranolol on perceived exertion soon after myocardial revascularization surgery. Med Sci Sports Exerc 1982;14: 276-80

21 Chow RJ, Wilmore JH. The regulation of exercise intensity by ratings of perceived exertion. Fournal of Cardiac Rehabilitation 1984;4:382-7.

22 Turkulin K, Zamlic B, Pegan U. Exercise performance an perceived exertion in patients after myocardial infarction.
In: Borg GAV, ed. Physical work and effort. Oxford: Pergamon Press, 1987:357-66.

23 Connolly DA, Fernhall B, McHugh $M$. The reliability of the RPE scale in a population with coronary heart disease. Sports Medicine, Training and Rehabilitation 1996;76:7-16.

24 Shephard RJ, Kavanagh T, Mertens DJ, Yacoub M. The place of perceived exertion ratings in exercise prescription for cardiac transplant patients before and after training. $B$ 7 Sports Med 1996;30:116-21.

25 Ekblom B, Goldbarg AN. The influence of training and other factors on the subjective rating of perceived exertion. Acta Physiol Scand 1971;83:399-406.

26 Sjoberg H, Frankenhaeuser M, Bjurstedt H. Interaction between heart rate, psychomotor performance and perceived effort during physical work as influenced by beta-adrenergic blockade. Biological Physiology 1979;8:3143.

27 Davies CTM, Sargeant AJ.The effects of atropine and practolol on the perception of exertion during treadmil exercise. Ergonomics 1979;22:1145-8.

28 Williams JG, Eston RG. Exercise intensity regulation In:Eston RG, Reilly T, eds. Kinanthropometry and exercise physiology laboratory manual: tests, procedures and data. London: E and FN Spon, 1996:221-35.

29 Eston RG, Davies BL, Williams JG. Use of perceived effor ratings to control exercise intensity in young healthy adults. Eur f Appl Physiol 1987;56:222-4.

30 Eston RG, Williams JG. Reliability of ratings of perceived effort for regulation of exercise intensity. Br $\mathcal{F}$ Sports Med 1988;22:153-4.

31 Department of Health. The health of the nation: a strategy for health in England. London: HMSO, 1992.

32 Shaper AG, Pocock SJ, Phillips AN, Walker A. A scoring system to identify men at high risk of a heart attack. Health Trends 1987;19:37-9.

33 American College of Sports Medicine. ACSM's guidelines for exercise testing and prescription. Philadelphia: Lea and Febiger, 1995:68-71.

34 Siconolfi SF, Cullinane EM, Carleton RA, Thompson PD. Assessing $\mathrm{VO}_{2}$ max in epidemiological studies: modification of the Astrand-Rhyming test. Med Sci Sports Exerc 1982;14:353-xx.

35 Noble BJ. Clinical applications of perceived exertion. Med Sci Sports Exerc 1982;14:406-11.

36 Dunbar CC, Robertson RJ, Baun R, Blandin MF, Metz RK, Burdett $\mathrm{R}$, et al. The validity of regulating exercise intensity by ratings of perceived exertion. Med Sci Sports Exerc 1992, 24:94-9.

37 Hetzler RK, Seip RL, Boutcher SH, Pierce E, Snead D, Weltman A. Effect of exercise modality on ratings of perceived exertion at various lactate concentrations. Med Sci Sports Exerc 1991;23:88-92.

38 Robertson RJ, Gillespie RL, McArthy J, Rose KD. Differentiated perceptions of exertion: Part 1: Mode of integration and regional signals. Percept Mot Skills 1979;49:683-9.

39 Smutok MA, Skrinar GW, Pandolf K. Exercise intensity: subjective regulation by perceived exertion. Arch Phys Med Rehabil 1980;161:569-74.

40 Anderson RL, Wilmore JH, Joyner MJ, Freund BJ, Hartzell $\mathrm{AA}$, Tod CA, et al. Effects of cardioselective and nonselective beta-adrenergic blockade on the performance of highly trained runners. Am f Cardiol 1985;55:149D-54D.

41 Kelly JG. Choice of selective versus nonselective betablockers: implications for exercise training. $A m \mathcal{F}$ Cardio 1985;55:162D-6D.

42 Derman WE, Sims R, Noakes TD.The effects of antihypertensive medications on the physiological response to maximal exercise testing. Pharmacology 1992;19:S122-7. 